\title{
IDŐJÁRÁS
}

Quarterly Journal of the Hungarian Meteorological Service

Vol. 125, No. 4, October-December, 2021, pp. 625-646

\section{Effect of the uncertainty in meteorology on air quality model predictions}

\author{
Zita Ferenczi*, Emese Homolya, Krisztina Lázár, and Anita Tóth
}

Hungarian Meteorological Service

Kitaibel P. str. 1, H-1024 Budapest, Hungary

*Corresponding author's E-mail: ferenczi.z@met.hu

(Manuscript received in final form September 30, 2021)

\begin{abstract}
An operational air quality forecasting model system has been developed and provides daily forecasts of ozone, nitrogen oxides, and particulate matter for the area of Hungary and three big cites of the country (Budapest, Miskolc, and Pécs). The core of the model system is the CHIMERE off-line chemical transport model. The AROME numerical weather prediction model provides the gridded meteorological inputs for the chemical model calculations. The horizontal resolution of the AROME meteorological fields is consistent with the CHIMERE horizontal resolution. The individual forecasted concentrations for the following 2 days are displayed on a public website of the Hungarian Meteorological Service. It is essential to have a quantitative understanding of the uncertainty in model output arising from uncertainties in the input meteorological fields. The main aim of this research is to probe the response of an air quality model to its uncertain meteorological inputs. Ensembles are one method to explore how uncertainty in meteorology affects air pollution concentrations. During the past decades, meteorological ensemble modeling has received extensive research and operational interest because of its ability to better characterize forecast uncertainty. One such ensemble forecast system is the one of the AROME model, which has an 11-member ensemble where each member is perturbed by initial and lateral boundary conditions. In this work we focus on wintertime particulate matter concentrations, since this pollutant is extremely sensitive to near-surface mixing processes. Selecting a number of extreme air pollution situations we will show what the impact of the meteorological uncertainty is on the simulated concentration fields using AROME ensemble members.
\end{abstract}

Key-words: chemical transport model, uncertainty in meteorology, ensemble technic, smog 


\section{Introduction}

Air pollution is a major environmental risk of our times, the reduction of which poses a great challenge on professionals and decision-makers equally (Lelieveld, 2017). High concentrations of air pollutants may directly impair human health (Landrigan, 2017), ecosystems (De Marco et al., 2019), and the built environment (Kucera and Fitz, 1995). Deposition processes may lead to harmful material getting into the surrounding environmental media - into the vegetation, waters, or soil -, where it can cause further damage (Moiseenko et al., 2018). Today a widening range of attention is given to air quality, and we have more and more advanced methodologies to assess the current status $(E E A, 2019)$ and tendencies of, and the expected changes in air pollution (Apte et al., 2017).

Although the most accurate information regarding the actual conditions in the air is gained by direct measurements, a comprehensive assessment of air quality today requires the use of specific air quality models (Rybarczyk and Zalakiviciute, 2018). Based on a mathematical interpretation of physical and chemical processes taking place in the air, air quality models define a relationship between the emitted pollutants and concentrations measured in the environment (Baklanov et al., 2014).

Therefore, they provide a suitable way for the tracking of the dispersion, chemical reactions, and deposition of air pollutants. Modern air quality models take many kinds of environmental processes into account, and their evolving complexity makes it possible for them to describe the real behavior of the natural systems more and more profoundly. However, no matter how sophisticated a model is, due to the high complexity of the natural systems and the feedbacks and non-linearities they involve, it is not able to describe all processes fully accurately, it is bound to use approximation and parameterization in its methods. Simulations of the models are therefore generally accompanied by a certain amount of uncertainty, that is dependent on the calculation methods, the accuracy of the input data, the geographical environment, the weather situation, and the resolution as well (Borrego et al., 2008). In the issue of the response of the air quality model to varying input data, it is essential to evaluate the reaction of the model to the changes in the emission or the meteorological data. The better understanding we have regarding the behavior, characteristics, and limits of our models, the more precisely we can define this uncertainty, which then provides us with the opportunity to estimate the expectable accuracy of our calculations beforehand.

One of the most important input data of the chemical transport models comes from the emission inventories, which latter are static databases for a specific year. Furthermore, emissions are not possible to be measured in most cases. The emission estimate is inevitably an inaccurate representation of the emission that actually occurred. In addition to the simulations, emission data with fine temporal (Menut et al., 2012) and spatial variations are expected. The uncertainty of the emission data depends not only on the category of the emission source but also on 
the contributing emission sources and their quantity. The assessment of uncertainty in the modeled forecasts in relation to the input uncertainty of the emission dataset has been analyzed in many papers (Napelenok et al., 2011; Holnicki and Nahorski, 2015).

The aim of this research was to analyze the Hungarian air quality from different aspects using up-to-date tools based on model simulations, where we focused primarily on weather elements that mostly influence dispersion processes in the air (Angevine, et al., 2014), their effects on concentrations evolving in the environment, and the modeling of critical air quality situations rising in special meteorological conditions. In our previous work (Homolya, 2021), a sensitivity analysis was carried out using the CHIMERE chemical transport model in order to examine, to what extent and how the key meteorological elements affect the evolving concentrations in the course of the modeling process. For this study, the values of the meteorological parameters were artificially modified. This modification was not physically consistent, but at that time ensemble members from AROME model were not available.

As a result of developments at the Hungarian Meteorological Service in recent years, AROME EPS has become available for sensitivity analyses. Using this new meteorological driver, physically consistent meteorological fields were available for our examination. In this work, we focus on wintertime particulate matter concentrations, since this pollutant is extremely sensitive to near-surface mixing processes. Three extreme air pollution situations were selected to examine the impact of the meteorological uncertainty on the simulated concentration fields.

\section{Materials and methods}

\subsection{Models}

For the examinations with the CHIMERE chemical transport model (Mailler et al., 2017), a domain covering Hungary and extending to almost the whole territory of the Carpathian Basin, with the borders of latitudes $45^{\circ}$ and $50^{\circ}$ and longitudes $14^{\circ}$ and $25^{\circ}$ (Fig. 1) was chosen to be the target area. The area bounded by the red line in Fig. 1 shows the calculation domain. The grid was defined the way that the spatial resolution fits that of the emission inventory data of EMEP $-0.1^{\circ}-$ which corresponds to roughly $10 \mathrm{~km}$ in the region of the Carpathian Basin. We have to emphasize that the analyses presented in this work refer to the area bounded by the blue line, which is smaller than the area bounded by the red line. The reason for this choice was that some unbalances might occur close to the border of the domain, arising from the boundary conditions. 


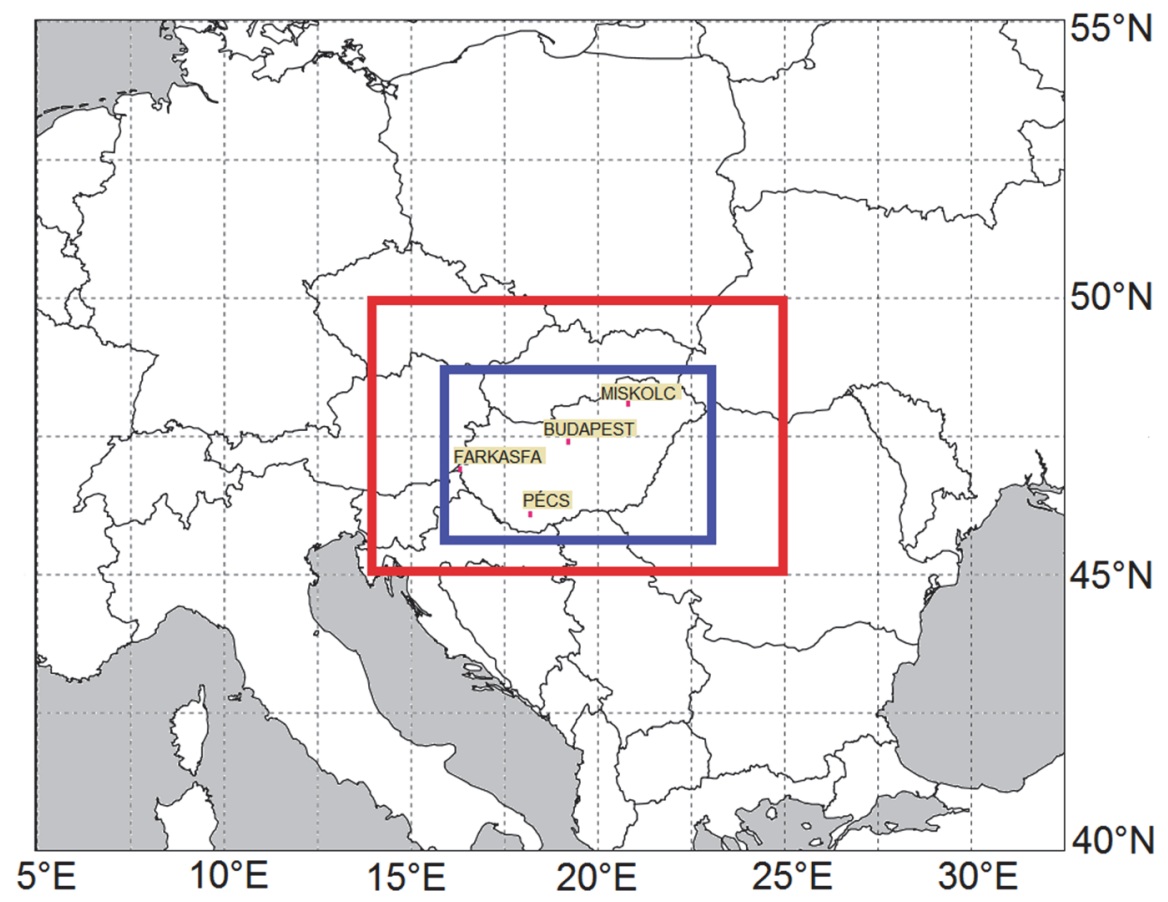

Fig. 1. The target domain for the analyses using the CHIMERE model and the location of the monitoring sites.

The gridded emission inventory of EMEP for the year 2015 was used in the simulations. The inventory data for nitrogen-oxides, volatile organic compounds, sulphur dioxide, ammonia, fine aerosol particles $\left(\mathrm{PM}_{2.5}\right)$, coarse aerosol particles $\left(\mathrm{PM}_{10}-\mathrm{PM}_{2.5}\right)$, and carbon-monoxide were taken into account in a $0.1^{\circ}$ spatial resolution. The EMEP emissions inventory, which includes annual total data, has to be converted to hourly data (Menut et al., 2012). During the time distribution of the emission data, seasonal, weekly, and hourly factors are used.

Data of biogenic emission was calculated by the MEGAN model (Guenther et al., 2006), which is a global model with a base resolution of $\sim 1 \mathrm{~km}$.

Meteorological data were provided by the AROME non-hydrostatic numerical weather prediction model of the Hungarian Meteorological Service in a 1-hour temporal and the $0.1^{\circ}$ spatial resolution of the EMEP grid. For CHIMERE, data is prepared by the built-in meteorological pre-processor, using the model's own diagnostic tool. One file in the database contains data for one single day. AROME/HU (Szintai et al., 2015) runs 8 times per day up to $36-48$ hours at $2.5 \mathrm{~km}$ horizontal resolution using 60 vertical levels over a domain including the Carpathian Basin. The initial conditions are prepared by optimal interpolation on the surface and local 3D-Var assimilating SYNOP, TEMP, AMDAR, GNSS ZTD measurements, and Mode-S MRAR data from the Slovenian network. The hydrometeors and snow evolve through the data assimilation (DA) cycle. Hourly lateral boundary conditions are taken from the ECMWF HRES forecast in time lagged mode. AROME-EPS is an 11-member forecast coupled to 18 UTC ECMWF ENS with a frequency of 3 
hours. The model runs at horizontal resolution of $2.5 \mathrm{~km}$ over a domain covering the Carpathian Basin. The forecasts are initialized at 00 UTC and range up to 48 hours.

For our chemical transport model calculations, the AROME and AROME-EPS run at 00 UTC and the model results of 00-24 UTC have been used. In our model simulations, the deterministic model is considered as benchmark results because this data is used in the operational air quality prediction. The originally fine resolution meteorological fields of the AROME and AROME-EPS model were interpolated to the CHIMERE grid, which was defined by the EMEP gridded emission data.

Boundary and initial conditions are needed to get appropriate model results. In our test cases, in the case of the first day, climatological data were used as initial conditions, and then the previous simulation produced the initial conditions for the next simulation. The climatological set of boundary conditions has been provided by the LMDz-INCA global model (Laboratoire de Météorologie Dynamique General Circulation Model coupled with INCA: Interaction with Chemistry and Aerosols) (Hourdin et al., 2006; Hauglustaine et al., 2004). Information concerning land cover has been provided by the USGS database (Loveland et al., 2000).

\subsection{Measurements}

Four monitoring stations with significantly different characteristics (population, type of station) were selected for the detailed analysis of three cities, Budapest, Miskolc, Pécs, and Farkasfa background monitoring station. The locations of the monitoring stations can be seen in Fig. 1 .

At several locations in Budapest $\left(525.1 \mathrm{~km}^{2}, 1756000\right.$ inhabitants), the monitoring of $\mathrm{PM}_{10}$ with fine temporal resolution started in 2007. Among the monitoring sites, the Gilice tér urban background station (located in the southeastern part of Budapest) was selected for our analysis, which is a standard meteorological and air quality monitoring station providing $\mathrm{PM}_{10}$ concentrations and detailed meteorological observations with good data coverage. This location is in the area of the Marczell György Main Observatory of the Hungarian Meteorological Service. The classification of this air quality monitoring site is suburban with a significant influence from major sources from the greater Budapest area.

Miskolc (236.7 km², 159000 inhabitants) is represented by the Búza tér station. The classification of the site is urban traffic with a significant contribution from traffic-related sources. Moreover, the whole city is located in an unfavourable geographical location in the valley of Sajó River surrounded by the Bükk Mountains. Its special orography contributes to the development of longlasting (several days up to weeks) and severe air pollution episodes.

In Pécs (162.8 km², 148000 inhabitants), the selected station (Boszorkány utca) is located in a suburban environment. The hourly $\mathrm{PM}_{10}$ data for our complex analysis have been available since 2009. One of the major industrial emission 
sources in this area is a coal-fueled power plant equipped with two modern electrostatic precipitators. This development further decreases the $\mathrm{PM}_{10}$ emissions in the city. However, compared to Miskolc, the city of Pécs has more favorable orography: the northern part of the city is bordered by the Mecsek Mountains, but the southern side is open and flat.

Farkasfa background air pollution monitoring station is located in the western part of Hungary, at the area of the Örség National Park. The station is surrounded by forest and no essential local source of air pollutants can be found nearby.

\subsection{Episode situations}

Three episode situations (January 6-13, 2020, January 17-22, 2020, and November 9-14, 2020) were analyzed in depth, when $\mathrm{PM}_{10}$ concentrations were over the threshold limit in Hungary. The synoptic events were anticyclonal in Central Europe during these periods (Fig. 2). A cold pool is a special meteorological situation that is related to inversion in the upper atmosphere and is coupled with low surface air temperatures. It most frequently evolves in areas that are surrounded by chains of mountains. Events in anticyclones trigger the development of cold pool as they foster downward motions in the air. By serving as a barrier for mixing motions, inversion causes the air to stabilize, and it hinders the movement of the air mass out of the basin.
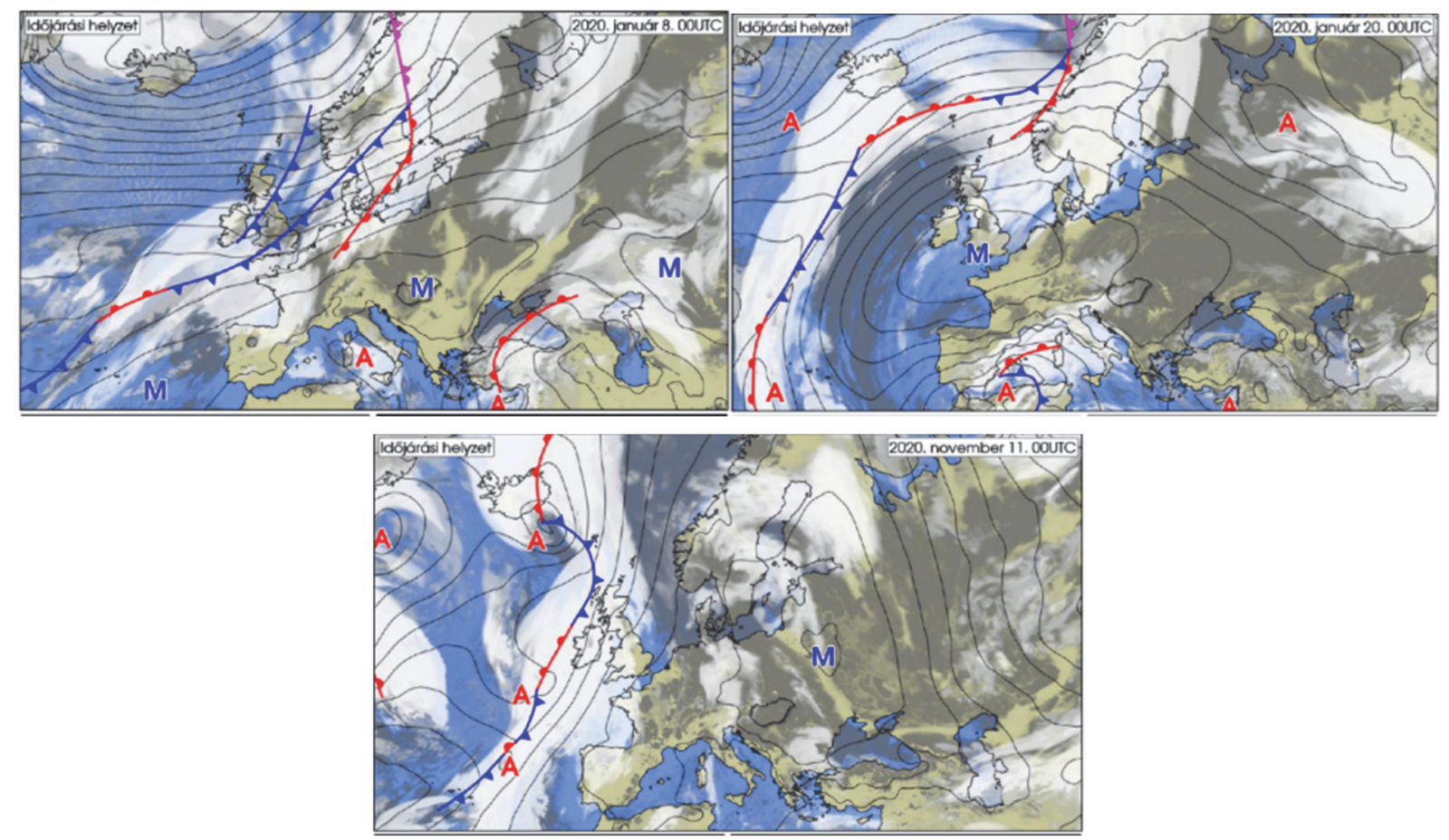

Fig. 2. Typical weather situations during the analyzed episode situations. (source: www.met.hu) 
During the time period January 6-13, 2020, an anticyclone was observed in Central Europe. The weather was quiet and uneventful in the first days of this time period, the sky was variably cloudy and the sun was quite often shining everywhere in the country. The sky was weakly cloudy, at night but temporary fog spots formed at dawn. In the middle of the period, the influence of a warm front was observed, and warm, moist air came into Hungary. Subsequently, a layer of clouds and fog formed during the nights in many places, which did not break up or only broke up later during the day in the eastern and northeastern parts of the country. In the rest of the country, the sky was clear due to the strengthening NW wind, but the extension of the clear region decreased day by day.

The following period (January 17-22, 2020) was heavily cloudy with misty, foggy weather, both at nights and during the days. It is important to mention that on January 19, a weak cold front arrived over the western counties and disbanded there, but it did not cause a significant change in the weather. The change was brought by another cold front, which arrived on January 22 from the north. It had already passed over the country, leaving a weakly cloudy, sunny weather behind.

During the next period (November 9-14, 2020), an extensive anticyclone was located again over Central Europe. It stretched from the Scandinavian Peninsula to the Balkans. A classic cold pool developed over the target area. The permanently cloudy, misty, foggy weather across the country was only interrupted during the day in some places in the western parts of the country. The turning point was a passing cold front that brought drier air.

\section{Results and discussion}

In this section, the effect of the meteorological parameters on the $\mathrm{PM}_{10}$ concentration values calculated by an air quality model will be presented. In our previous work (Ferenczi et al., 2020) we found, that the wind speed, the boundary layer (PBL) height, and the precipitation affected the prediction of the $\mathrm{PM}_{10}$ concentrations the most. In this work, the impact of the meteorological uncertainty on the simulated concentration fields was determined using AROME numerical weather prediction model's ensemble members. The analysis focused on the effects of the wind speed and the boundary layer height. In this work, the effect of precipitation was not examined, because in these episode situations no precipitation was reported. Three episode situations were selected for the analysis. The characteristics of these episode situations were described in the previous section.

\subsection{Effect of the uncertainty in meteorology on air quality model predictions}

We calculated the areal average differences between the various EPS and the deterministic values of the meteorological parameters and the $\mathrm{PM}_{10}$ concentration over the domain covering Hungary. All the three episode situations have been 
analyzed with this method. The time series of these areal average differences and also of the deterministic values are visualized in graphs.

First we conclude the results of the six-day period in November 2020. (Fig. 3) On the last two days, the deterministic PBL heights are much higher than the EPS values in the middle of the day, that is why we see large negative differences in the figure around noon. That means that the maximum PBL height was underestimated by the EPS members. At the end of the day on November 13, all the EPS areal averages are above the deterministic value. The maximum of the positive areal average differences was $+49 \mathrm{~m}$ and the largest negative deflection was $-93 \mathrm{~m}$. Referring to the wind speed areal averages we can say, that the differences stayed mostly between $+/-0.1 \mathrm{~m} / \mathrm{s}$ in the first and between $+/-0.2 \mathrm{~m} / \mathrm{s}$ in the second half of the period. On November 13, during the first 8 hours, the deterministic areal averages were lower than all the other EPS values. The maximum value of the positive differences is $+0.3 \mathrm{~m} / \mathrm{s}$ and the maximum of the negative differences is $-0.2 \mathrm{~m} / \mathrm{s}$. When the PBL height or wind speed differences were large, all the EPS members were deflected in the same direction from the deterministic value. The areal average $\mathrm{PM}_{10}$ concentrations of the EPS members differ mostly between $+/-1 \mu \mathrm{g} / \mathrm{m}^{3}$ from the deterministic values in the first part of the period. With time, larger values appear, and the EPS members also differ more from each other. The maximum deflection is $+2.4 \mu \mathrm{g} / \mathrm{m}^{3}$ in the positive direction and in $-3.3 \mu \mathrm{g} / \mathrm{m}^{3}$ the negative direction. In the morning (from 6 to 12 ) of November 13, all the EPS values were lower than the deterministic concentration. This can be explained by the behavior of the areal average wind speeds: on this day, during the first 8 hours, the deterministic wind speeds were lower than any other EPS wind speeds. We were interested in how the daily averages of the PBL height, wind speed, and $\mathrm{PM}_{10}$ concentration changed on this day over the country. We visualized the deterministic daily averages and the differences between the EPS daily averages and deterministic values on maps. The maps relating to the $\mathrm{PM}_{10}$ concentration can be seen in Fig. 4. In the first map we see, that the daily, deterministic $\mathrm{PM}_{10}$ concentrations were above $40-50 \mu \mathrm{g} / \mathrm{m}^{3}$ in the eastern half of the country. In the other, difference-maps we see, that the EPS values differed with more than $+/-8 \mu \mathrm{g} / \mathrm{m}^{3}$ in this eastern part of the modeled region. Where the deterministic $\mathrm{PM}_{10}$ concentrations are relatively high, there the EPS members show larger differences. Although there are extended areas showing positive differences, we can still have an impression, that over the country the negative differences (green colours) dominate. 
A)

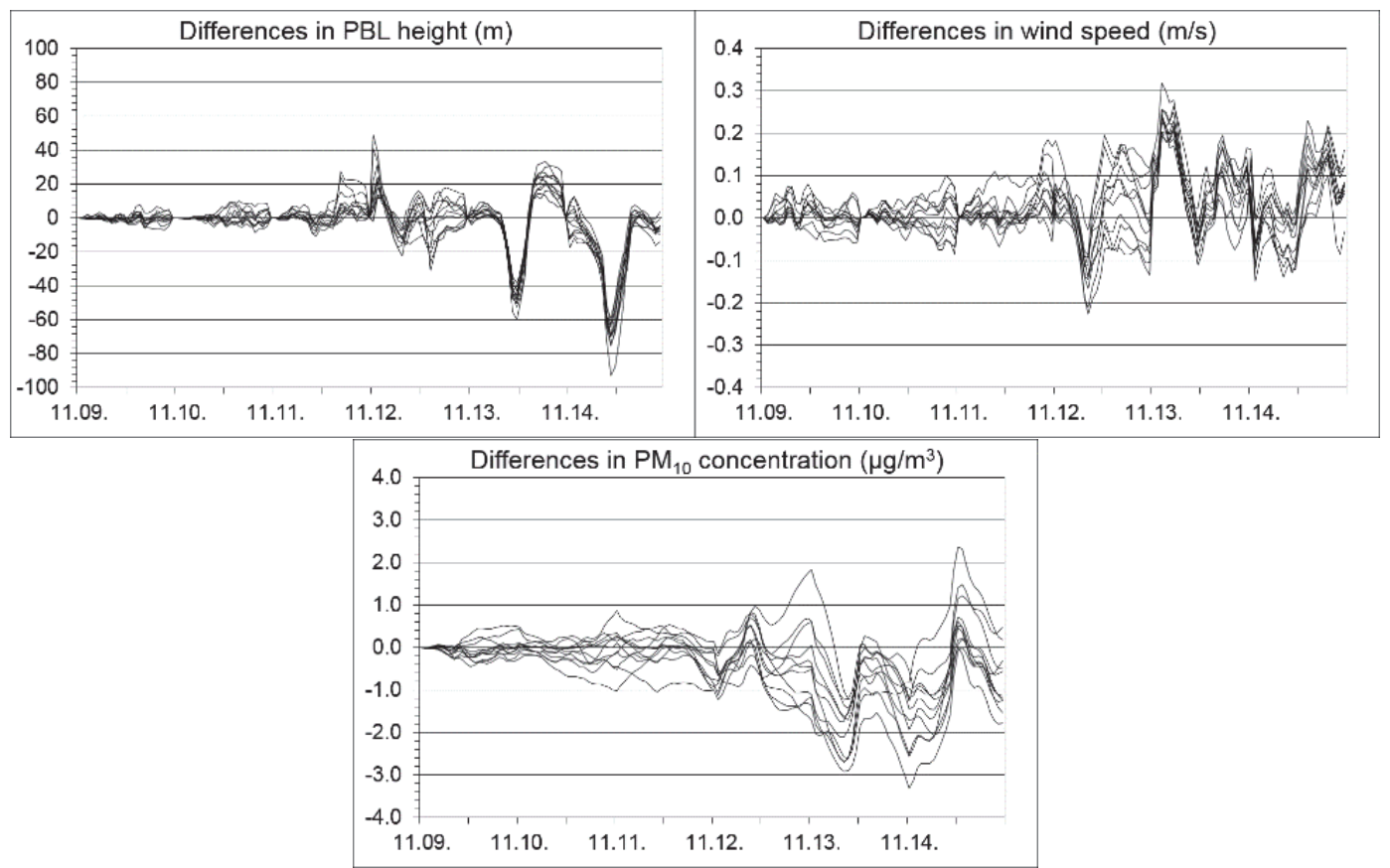

B)

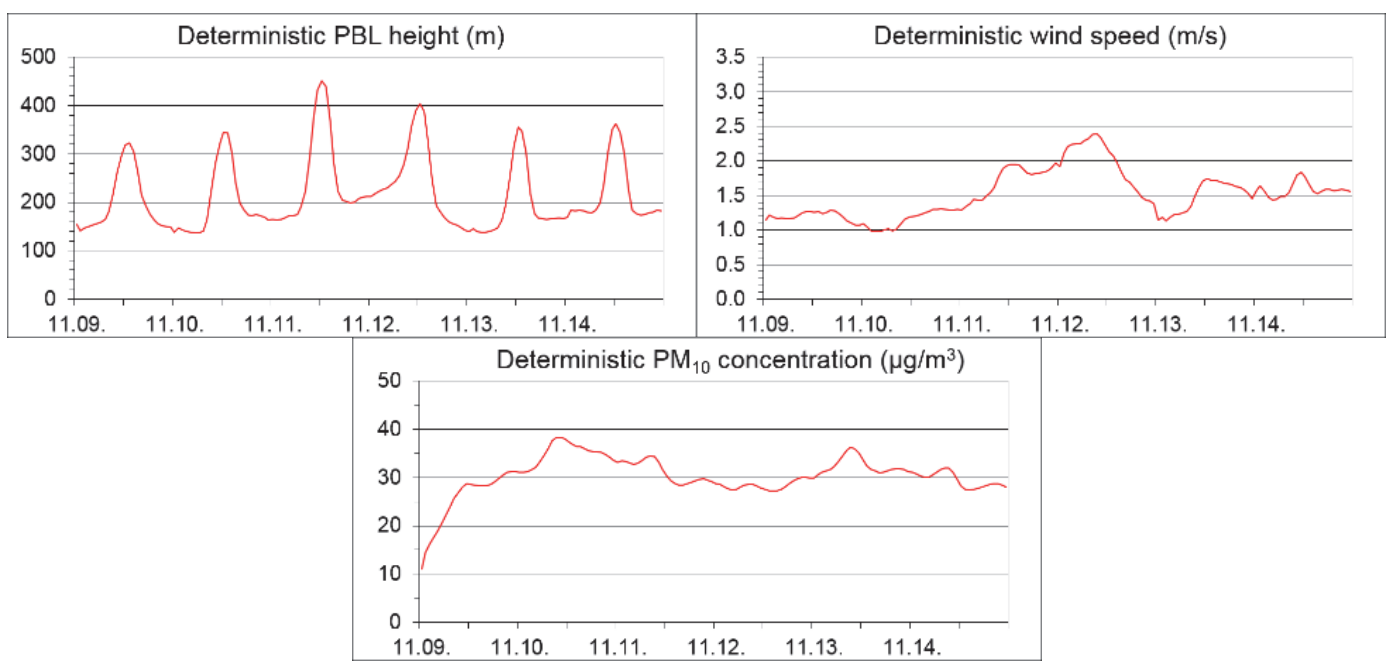

Fig. 3. A) Boundary layer height, wind speed, and $\mathrm{PM}_{10}$ differences between EPS members and deterministic values. B) Deterministic boundary layer height, wind speed, and $\mathrm{PM}_{10}$ values (areal averages, November 9-14, 2020). 


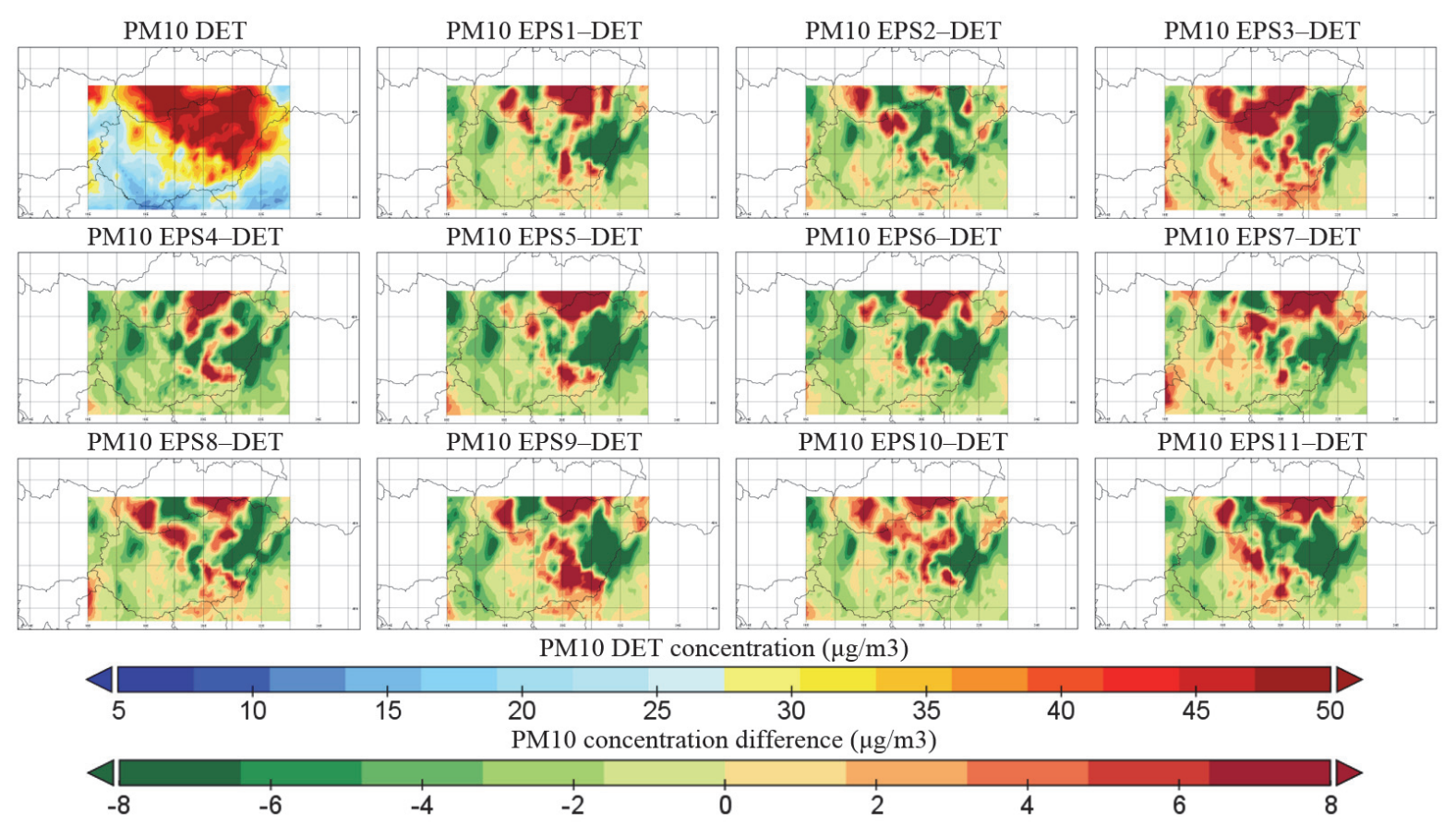

Fig. 4. Maps of deterministic daily average $\mathrm{PM}_{10}$ concentrations (first) and the difference between the EPS and the deterministic daily averages (others). Positive differences are red, negative differences are green. November13, 2020.

The next period is the January 6-13, 2020. (Fig. 5) The PBL height differences stayed mostly between $+/-20 \mathrm{~m}$, only on January 11 were larger differences. On this day, the extent of the deterministic planetary boundary layer was the largest. The maximum value of the positive differences is $+43 \mathrm{~m}$, in the negative direction the largest deflection was $-38 \mathrm{~m}$. The wind speed areal average differences are mostly between $+/-0.2 \mathrm{~m} / \mathrm{s}$. On January 11 , the differences are higher, there are some EPS members which differ nearly $+/-0.3 \mathrm{~m} / \mathrm{s}$ from the deterministic value. The maximum of the positive wind speed differences was $+0.3 \mathrm{~m} / \mathrm{s}$, in the negative direction the maximum deflection was $-0.3 \mathrm{~m} / \mathrm{s}$. The differences in the $\mathrm{PM}_{10}$ concentrations stayed mostly between $+/-1 \mu \mathrm{g} / \mathrm{m}^{3}$, but in some hours, the differences are near to the $+/-2 \mu \mathrm{g} / \mathrm{m}^{3}$ values. The maximum of the positive differences was $+1.9 \mu \mathrm{g} / \mathrm{m}^{3}$ and of the negative differences was $-3.5 \mu \mathrm{g} / \mathrm{m}^{3}$. To conclude, we can say that the largest differences were on January 11. This can be due to a cold front reaching the country on this day. We can see, that the deterministic wind speed and also the PBL height reached maximum values on this day, and the EPS members showed high variability around these maximum values. However, we could not detect especially large spread in the EPS $\mathrm{PM}_{10}$ concentrations on this day. 
A)

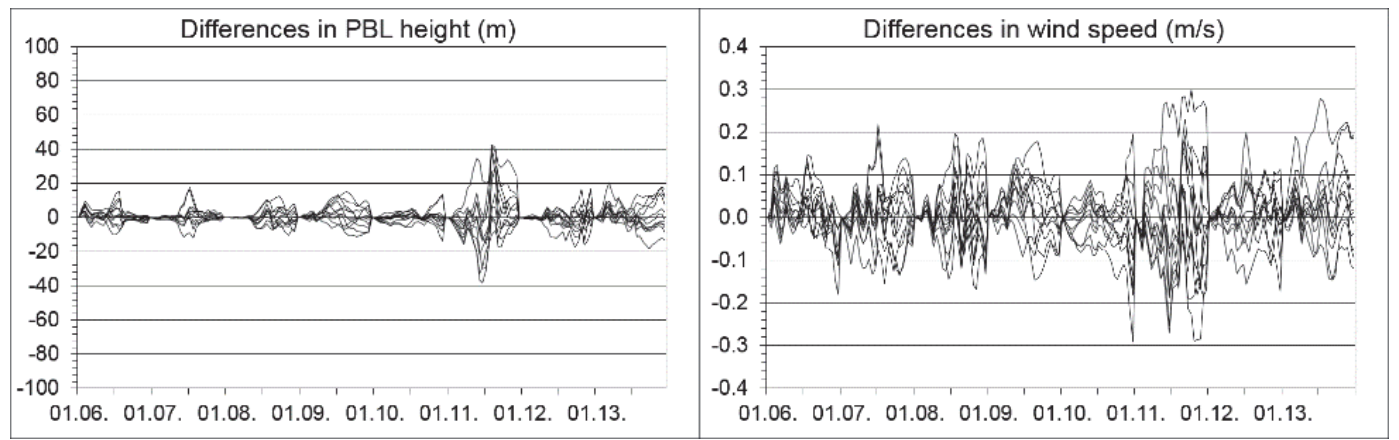

01.06. 01.07. 01.08. 01.09. 01.10. 01.11. 01.12. 01.13.

01.06. 01.07. 01.08. 01.09. 01.10. 01.11. 01.12. 01.13

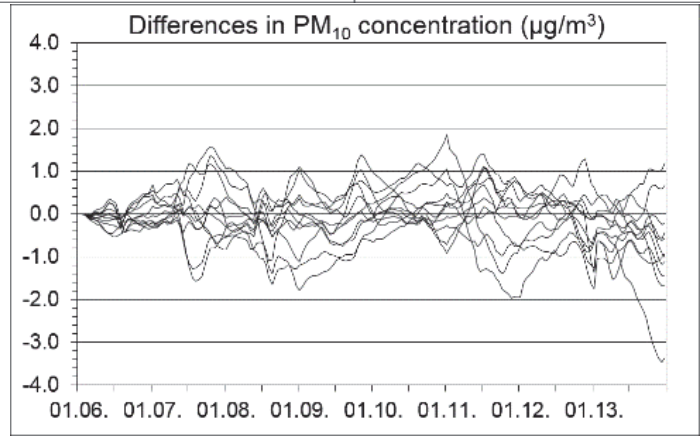

B)

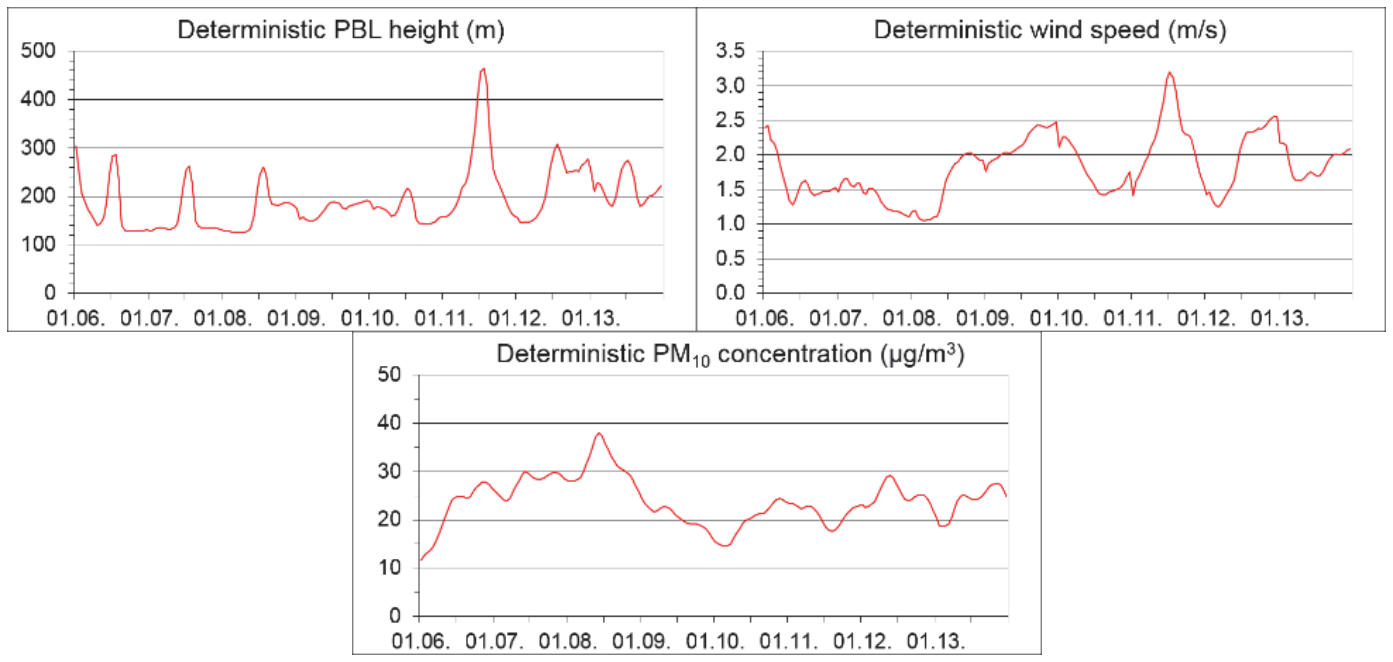

Fig. 5. A) Boundary layer height, wind speed, and $\mathrm{PM}_{10}$ differences between EPS members and deterministic values. B) Deterministic boundary layer height, wind speed, and $\mathrm{PM}_{10}$ values (areal averages, January 6-13, 2020.).

Lastly we conclude the information about the period January 17-22, 2020. (Fig. 6) Usually the PBL height deflections stayed between $+/-20 \mathrm{~m}$, but there are EPS members which differ in a larger magnitude mostly near the end of the day. The largest difference was $+121 \mathrm{~m}$, in the other direction $-46 \mathrm{~m}$ was the highest difference. Most of the wind speed differences are in the range of $+/-0.2 \mathrm{~m} / \mathrm{s}$. The largest, positive deflection was $+0.6 \mathrm{~m} / \mathrm{s}$, the largest negative 
difference was $-0.5 \mathrm{~m} / \mathrm{s}$. In case of the $\mathrm{PM}_{10}$ concentrations, the variation between the EPS members stayed large during the whole period apart from the first few hours. The differences did not cross the $2 \mu \mathrm{g} / \mathrm{m}^{3}$ value in the positive direction. The largest positive difference was $+1.5 \mu \mathrm{g} / \mathrm{m}^{3}$ and the largest negative was $-2.5 \mu \mathrm{g} / \mathrm{m}^{3}$ during the period. To conclude we can say, that most of the EPS members which on average showed positive areal average differences in PBL height and wind speed compared to the deterministic value, are the members, which showed negative $\mathrm{PM}_{10}$ differences. In the end of the period, the PBL height and wind speed differences are large and show high variability, but we see that the $\mathrm{PM}_{10}$ concentration differences are smaller than on the days before.

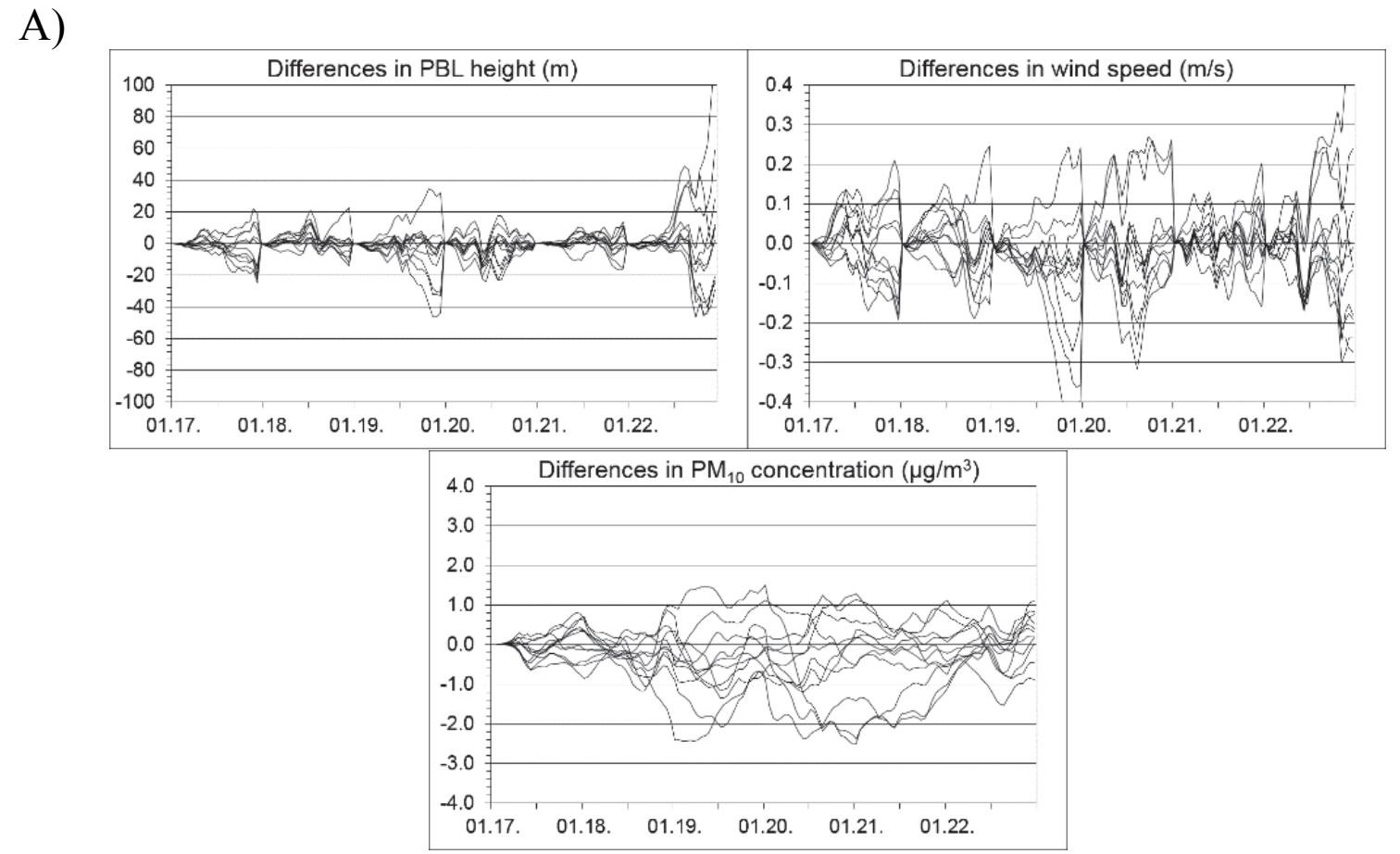

B)

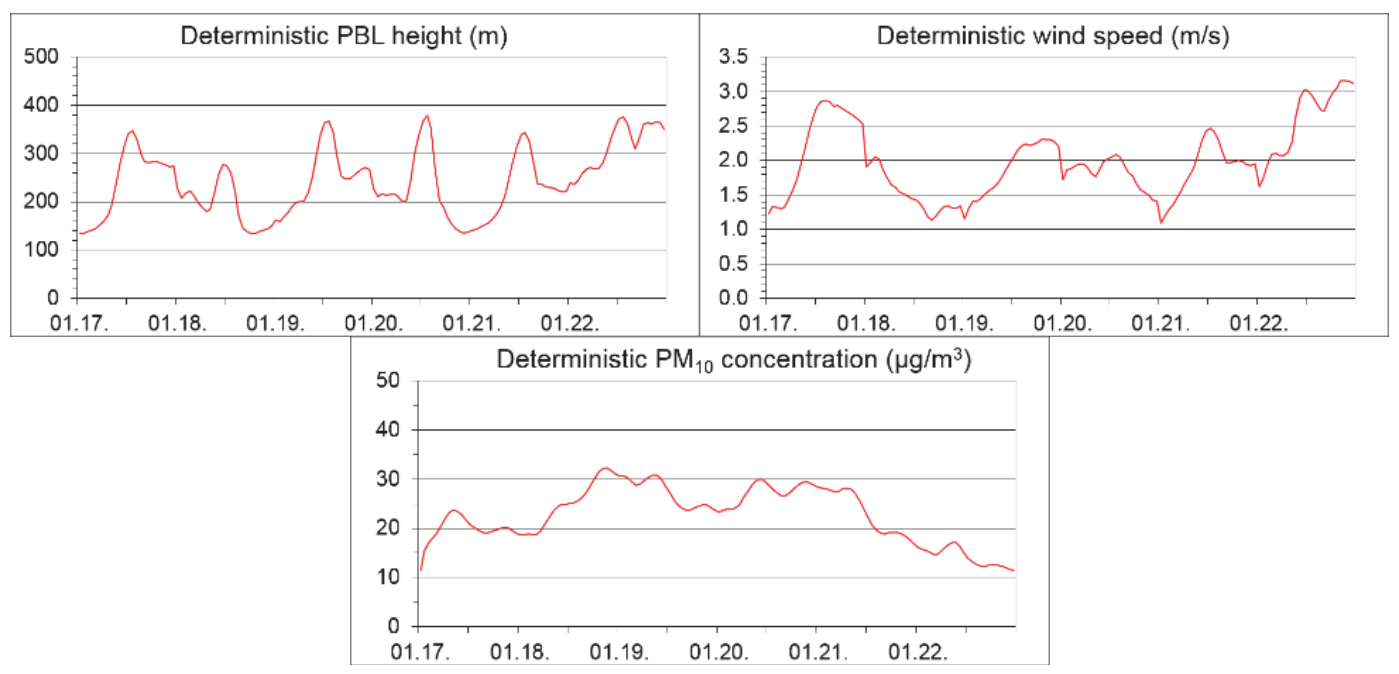

Fig. 6. A) Boundary layer height, wind speed, and $\mathrm{PM}_{10}$ differences between EPS members and deterministic values. B) Deterministic boundary layer height, wind speed, and $\mathrm{PM}_{10}$ values (areal averages, January 17-22, 2020). 
In terms of the areal averages, the variability in the meteorological data is showing itself in the $\mathrm{PM}_{10}$ concentration predictions. While the differences between the meteorological inputs (deterministic and EPS) in case of the PBL height and wind speed decrease in some hours during the examined periods, the implied $\mathrm{PM}_{10}$ concentration differences are large circa from the second day of each period, and the spread of the differences stays large until the end of the period. It is important to mention that the differences in wind fields could impact the advection or transport of pollutants from the sources. The differences which occur in the trajectories of the air parcels lead to changes in the concentration fields.

Finally, we examined the behavior of the EPS and deterministic PBL height, wind speed, and $\mathrm{PM}_{10}$ concentration values in four monitoring stations: Budapest, Miskolc, Pécs, and Farkasfa. To sum up we can say that the PBL height differences varied between $+/-200 \mathrm{~m}$ on the 4 monitoring stations, the wind speed differences stayed mostly between $+/-1 \mathrm{~m} / \mathrm{s}$, and the differences of the $\mathrm{PM}_{10}$ concentrations fell usually in the $+/-10 \mu \mathrm{g} / \mathrm{m}^{3}$ range. It is difficult to say that the differences in the gridcells of the stations got generally larger with time, because there were some cases relating to all of the examined parameters, when larger deflections from the deterministic values and larger variety within the values of the different EPS members arose in the first part of the period. In case of the PBL height, the differences were in general always large in the hours around noon. The various EPS members differed more in the maximum extension of the PBL from the deterministic value. Generally, there is a smaller variation in case of Farkasfa, however, large differences from the deterministic values can occur here too. The variation of the differences was smaller in Pécs than in the other urban stations. From the examined parameters the wind speed differences showed the largest variation during the three episode situations. Variations in the wind speed values had a more significant effect on the variation in the $\mathrm{PM}_{10}$ concentrations. Small differences in wind fields over areas with high emission can have notable impact on dilution and air parcel composition.

\subsection{Effect of the EPS meteorology on the air quality forecast}

The impact of EPS meteorology was investigated at three urban and one background stations. The three city stations are Gilice tér in Budapest, Búza tér in Miskolc, and Boszorkány utca in Pécs, and the background station is Farkasfa. We chose points far apart. The type, geographical location, and emission impact of the designated stations are also different, as shown in the previous chapter.

First, we examined the timelines to see if we could improve $\mathrm{PM}_{10}$ forecasting using EPS meteorology. AROME-EPS prediction is made with perturbed initial and lateral boundary conditions. The set of forecasts, produced in this way, presents several scenarios. From these we can also deduce the probability and uncertainty of weather events. Ensemble predictions also have the advantage of predicting extreme events, such as predicting air pollution peaks. 
In our case, we examined only three periods and four locations, but the standard deviation of EPS members did not prove to be widespread enough to adequately predict certain concentrations of pollutants. The application of EPS meteorology did not significantly improve the prediction of $\mathrm{PM}_{10}$ (Fig. 7). The results of this examination demonstrate that the success of air pollution forecast is affected by not only the accurate meteorological parameters but the perfect emission pattern of sources as well. The presented examples show that we have to improve or rethink how to prepare hourly emission data from the yearly amount. Of course, the accurate meteorological forecast is also a basis of a good air quality forecast, but in our case, the emission data is the weakness of our forecasting system.

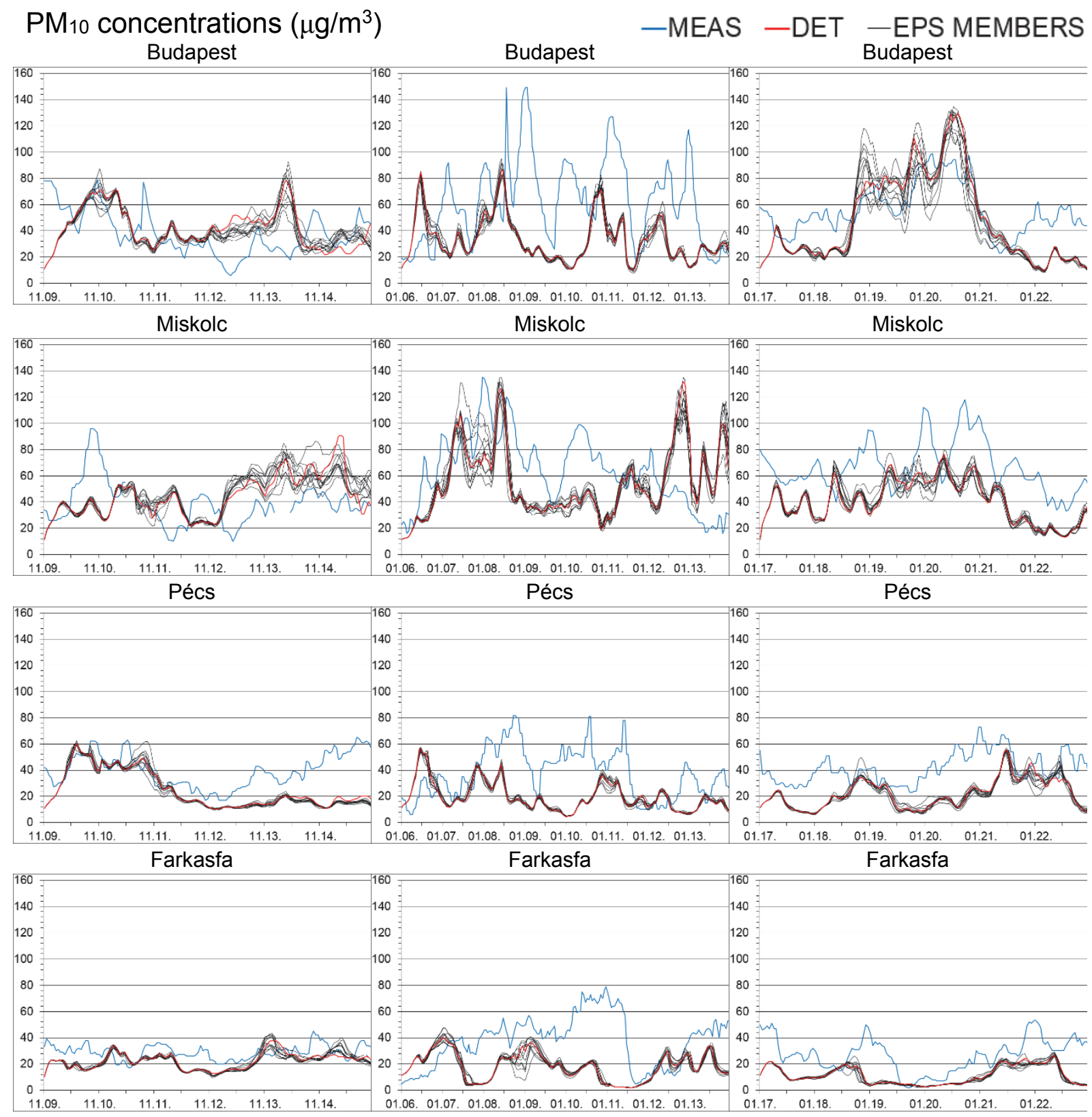

Fig. 7. Modeled and measured $\mathrm{PM}_{10}$ concentrations at Budapest, Gilice tér, Miskolc, Búza tér Pécs, Boszorkány utca, and Farkasfa stations (Source of measured data: Hungarian Air Quality Network). 
Generally, winter weather patterns provide more favorable conditions for critical air quality situations coupled with high concentrations of $\mathrm{PM}_{10}$ to occur than summer weather patterns, which can basically be put down to the different emission and meteorological characteristics. Next, we carried out a sensitivity analysis with the aim to prove that the role of meteorology is significant in the formation of air pollution in winter. It should be emphasized, that the performance of a model may depend on the geographical domain, which makes the target area relevant in the process of investigating the model characteristics. The sensitivity analysis proved to be an efficient method to demonstrate the strong effects of local meteorological parameters including the parameters principally responsible for the dispersion and dilution processes of air pollutants, namely wind speed and planetary boundary layer height on the evolving concentrations in the environment.

Time series were selected from the 3 episode situations for every 4 geographical points, when there was light and strong wind speed and low and high PBL height values (Tables 1 and 2). For these time periods, the differences between the two wind speed EPSs and PBL height EPSs extremes were determined and than compared to the appropriate $\mathrm{PM}_{10}$ concentrations. By extremes we mean which EPS gave the lowest values most often and which EPS gave the highest values most often compared to the other EPS members. With this analysis, the effects of wind speed and PBL height on $\mathrm{PM}_{10}$ concentrations were demonstrated. The used definition of light wind: $<2 \mathrm{~m} / \mathrm{s}$, strong wind: $>2 \mathrm{~m} / \mathrm{s}$, low PBL height: $<400 \mathrm{~m}$, and high PBL height: $>400 \mathrm{~m}$.

Table 1. Analyzed time periods for the effect of wind speed

\begin{tabular}{ccccc}
\hline \hline & Budapest & Miskolc & Pécs & Farkasfa \\
\hline \hline \multirow{2}{*}{ Light wind } & January 19-21, & November 13-15, & January 21-22, & November 12-15, \\
& 2020 & 2020 & 2020 & 2020 \\
\multirow{2}{*}{ Strong wind } & November 12-13, & January 09-12, & November 12-13, & January 19-20, \\
& 2020 & 2020 & 2020 & 2020 \\
\hline
\end{tabular}

The effect of wind speed is to cause the accumulated air pollutants to diffuse, thereby leading to an improvement in air quality and vice versa, decreasing wind speeds favor the accumulation of pollutants and induce a decline in air quality. First the effect of light wind on the $\mathrm{PM}_{10}$ concentration was analyzed (Fig. 8). The first line of Figure 8 shows the two EPSs that gave the lowest wind speed value most often and the highest wind speed value most often when low wind speed was examined. The same graphs show the $\mathrm{PM}_{10}$ concentrations for these EPSs. The second line of the figure shows the difference between the wind speeds and the difference between the $\mathrm{PM}_{10}$ concentrations of the aforementioned EPSs. Thus, the change in $\mathrm{PM}_{10}$ concentration caused by wind speed is illustrative. In the case 
of light wind, the $\mathrm{PM}_{10}$ concentration responds to small changes in wind speed with a significant adjustment. In the case of the presented examples, a $1 \mathrm{~m} / \mathrm{s}$ increase in wind speed can result in a decrease in the $\mathrm{PM}_{10}$ concentration up to $10 \mu \mathrm{g} / \mathrm{m}^{3}$. On the contrary, a $1 \mathrm{~m} / \mathrm{s}$ decrease in wind speed can result in an increase in the $\mathrm{PM}_{10}$ concentration up to $5 \mu \mathrm{g} / \mathrm{m}^{3}$. Based on Fig. 8 , it can be said, that in the case of light wind, the prediction of $\mathrm{PM}_{10}$ concentration is very sensitive to changes in wind speed.

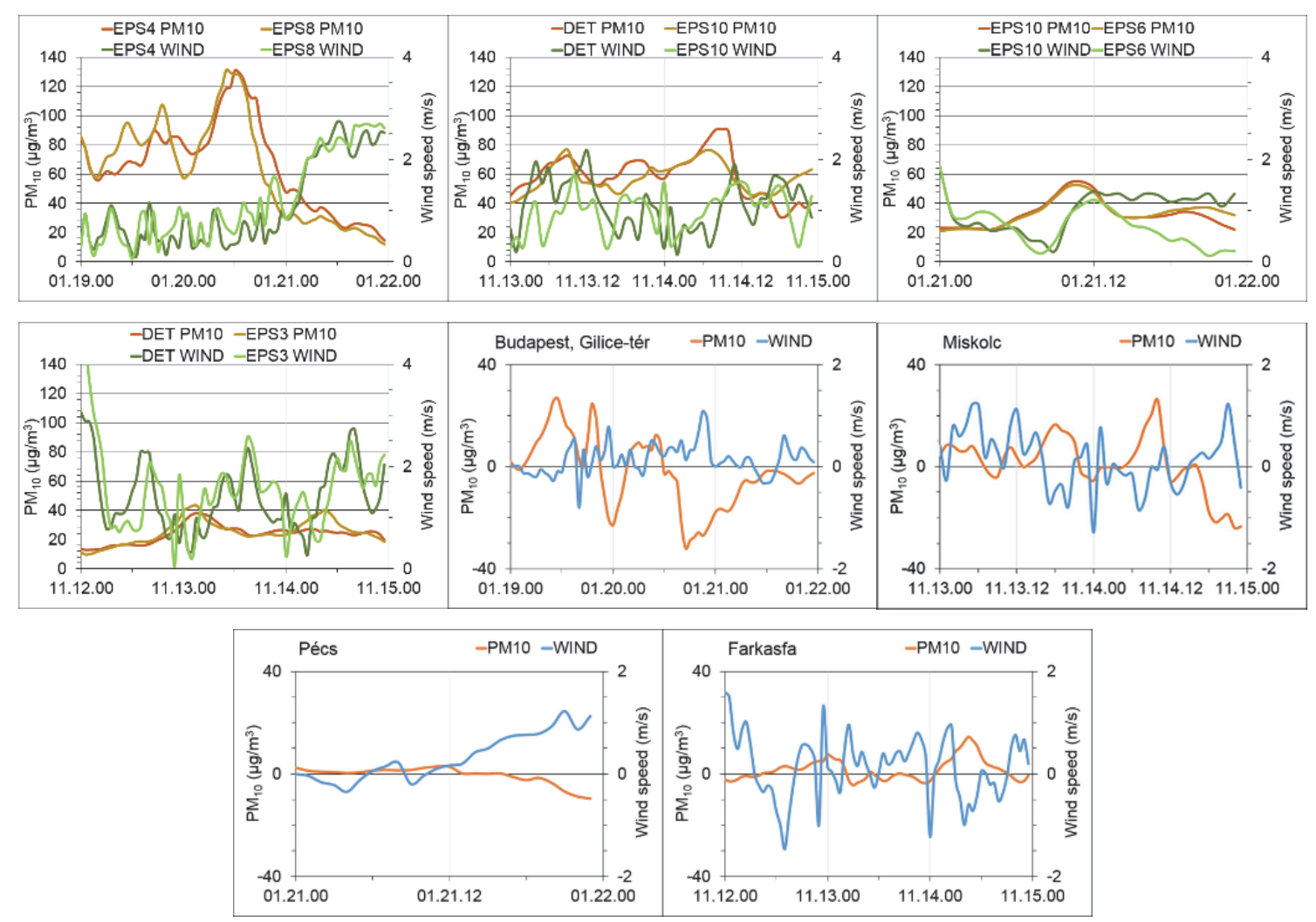

Fig. 8. Effect of the wind speed change on the change in $\mathrm{PM}_{10}$ concentration at several geographic locations (in case of light wind speed).

Then the effect of strong wind on the $\mathrm{PM}_{10}$ concentration was also analyzed (Fig. 9). The first line of Fig. 9 shows the EPSs giving most often the highest and most often the lowest wind speeds, as well as PM $_{10}$ values for the same EPSs. The second line shows the difference between the wind speeds and the difference between the $\mathrm{PM}_{10}$ concentrations. In this case, the response of the $\mathrm{PM}_{10}$ concentration change to the wind speed change is not as clear as in the case of light wind speed change, but it can be noted that the effect is not negligible. However, in some cases, a strong wind speed can also increase $\mathrm{PM}_{10}$ concentrations, as a result of an increased suspension of particles from ground surfaces (Kukkonen et al., 2005). 

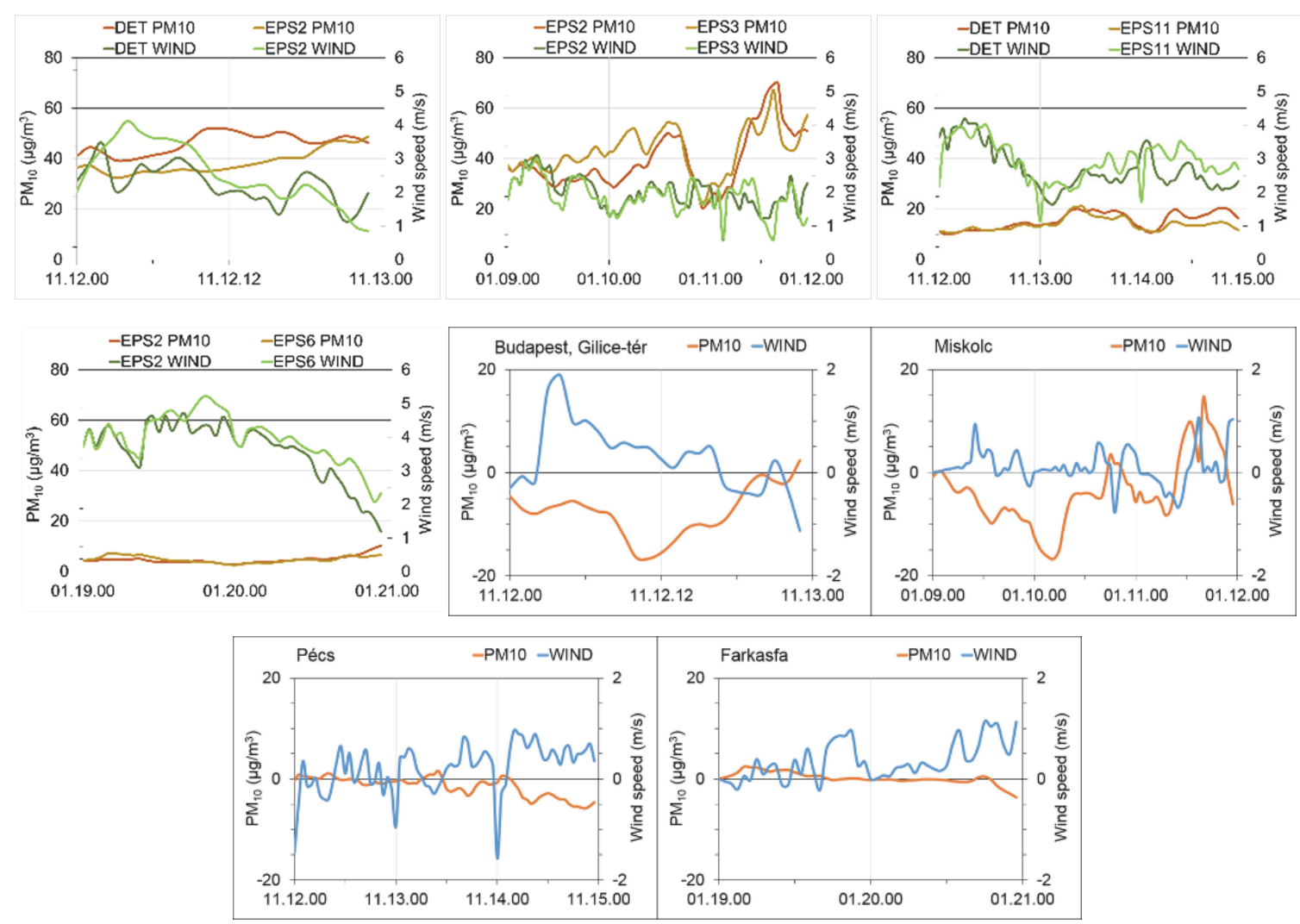

Fig. 9. Effect of the wind speed change on the change in $\mathrm{PM}_{10}$ concentration at several geographic locations (in case of strong wind speed).

Results show that differences in the concentration fields due to the modified meteorology (using EPS members) are more pronounced in the case of lower wind speeds than they are in the case of higher wind speeds. We have to note that the changes in $\mathrm{PM}_{10}$ concentrations were the most significant at the Budapest location. It is well trackable in model simulations that by low wind speeds pollutants start accumulating in the air rapidly, and it could be the explanation of this effect.

Table 2. Analyzed time periods for the effect of PBL height

\begin{tabular}{ccccc}
\hline \hline & Budapest & Miskolc & Pécs & Farkasfa \\
\hline \hline \multirow{2}{*}{ Low PBL height } & January 21-23, & January 17-19, & November 13-15, & November 13-15, \\
& 2020 & 2020 & 2020 & 2020 \\
High PBL & November 13-15, & January 21-23, & January 19-21, & November 11-13, \\
height & 2020 & 2020 & 2020 & 2020 \\
\hline
\end{tabular}


Pollutant, especially PM concentrations in the environment are largely affected by the boundary layer height as well (Du et al., 2013). Results show that an increasing boundary layer height is coupled with the decrease of pollutant concentrations and, on the other hand, a decrease in the planetary boundary layer height leads to a definite increase in concentrations. However, this general conclusion can be modified by the very extreme meteorological situation during cold pools, when the predicted planetary boundary layer height is extremely low $(<400 \mathrm{~m})$. First, the effect of low PBL height was analyzed on the $\mathrm{PM}_{10}$ concentration (Fig. 10). The expected effect that the increasing boundary layer height can cause decreasing $\mathrm{PM}_{10}$ concentration and vice versa is not clear in all cases in the case of low PBL height. A low boundary layer would constrain pollutants to the low surface layer and restrict the diffusion and dispersion of air pollutants. Our examination showed that a small change in the boundary layer height has a small effect on $\mathrm{PM}_{10}$ concentration. In our case studies, the negative connection was the strongest in the case of Pécs and the weakest in the case of Farkasfa. The first row of Fig. 10 shows the EPSs with most often the highest and most often the lowest PBL heights and the associated $\mathrm{PM}_{10}$ concentrations. The second line shows the difference between the PBL heights and the difference between the $\mathrm{PM}_{10}$ concentrations.
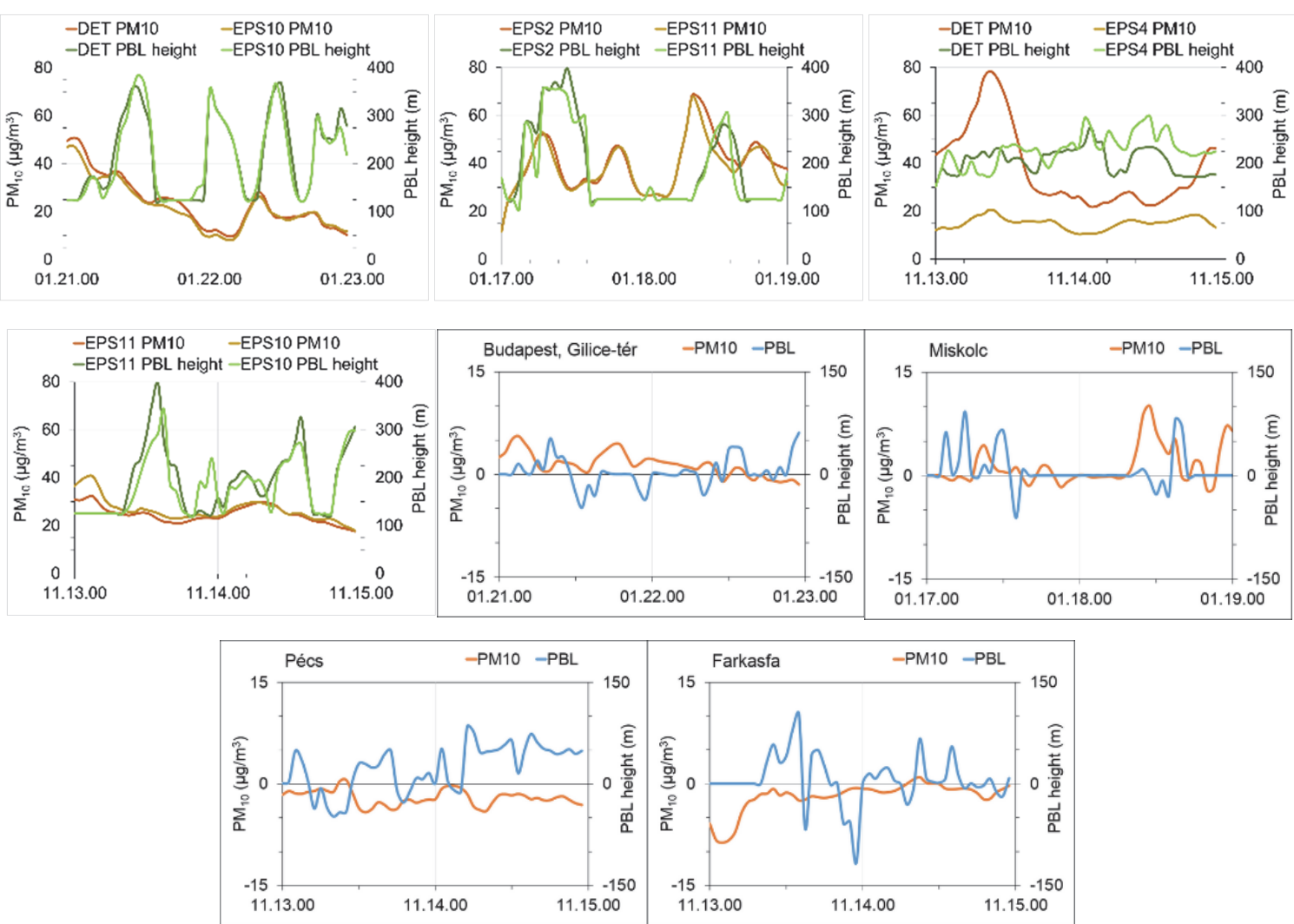

Fig. 10. Effect of the PBL height change on the change in $\mathrm{PM}_{10}$ concentration at several geographic locations (in case of low PBL height). 
As a next step, the effect of higher PBL height was also analyzed on the $\mathrm{PM}_{10}$ concentration (Fig. 11). Inverse relationship between boundary layer depth and $\mathrm{PM}_{10}$ concentration was found. This relationship is stronger when the PBL height is higher than $400 \mathrm{~m}$, because in this situation the decrease or increase of this layer could be more significant. The first row of Fig. 11 shows the EPSs with the most common highest and the most common lowest PBL heights, in the case of high PBL heights, and the corresponding $\mathrm{PM}_{10}$ concentrations. The second line of the figure shows the difference between these values.

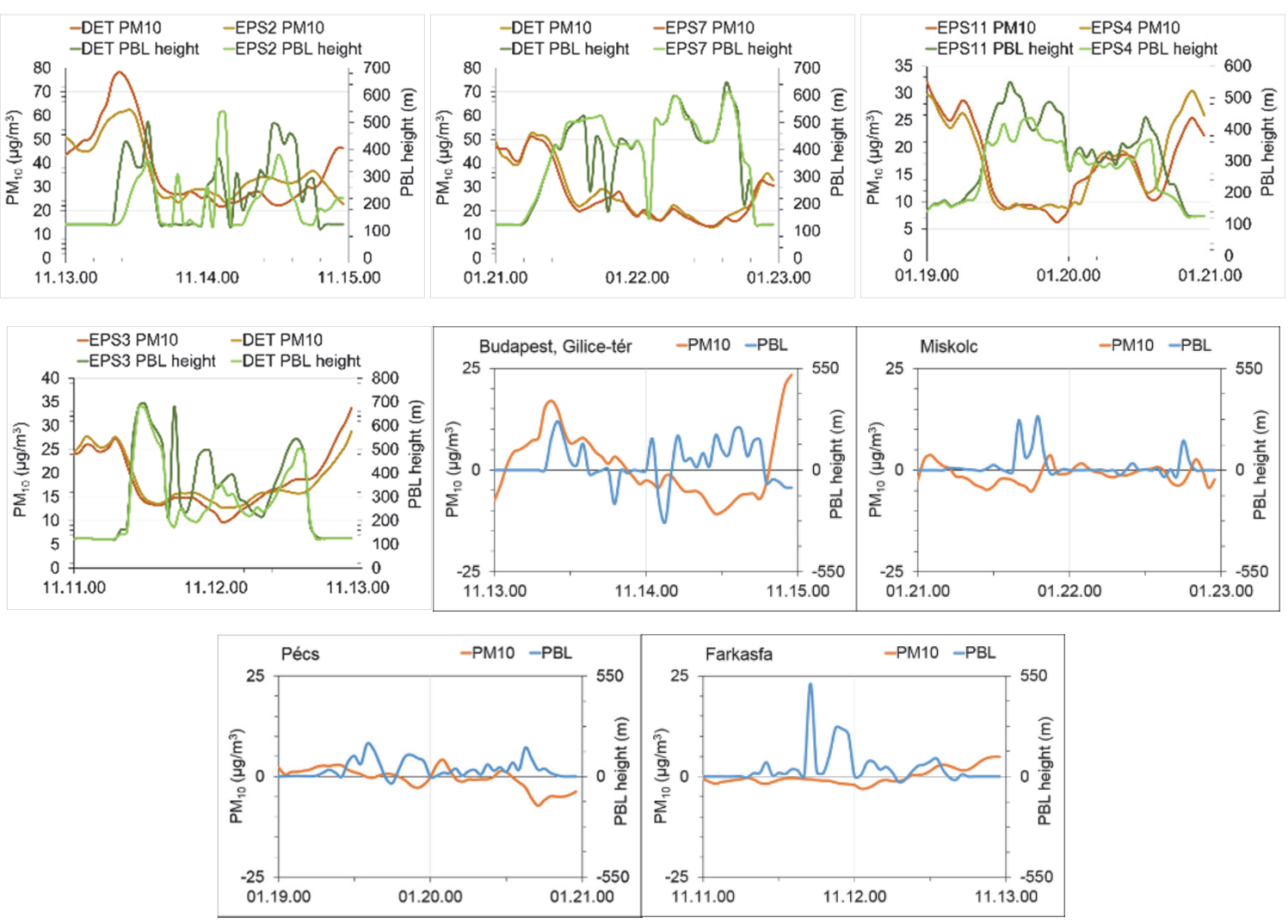

Fig. 11. Effect of the PBL height change on the change in $\mathrm{PM}_{10}$ concentration at several geographic locations (in case of high PBL height)

According to simulation results of the CHIMERE model, it is apparent that the response of the model is stronger for the decrease than for the increase of the boundary layer height, which means that the accumulation of air pollutants is more intense with the diminishing boundary layer than the dilution of pollutants is when the boundary layer height increases. We also have to note that the numerical weather prediction models determine the PBL height using different parameterization schemes, this fact can also affect the results of this type of analysis. The AROME numerical weather prediction model calculates the PBL height using the TKE scheme (Szintai et al., 2015). 
In this section, the effect of meteorological parameters on the $\mathrm{PM}_{10}$ concentration was analyzed separately. The effect of different meteorological situations (represented by a given EPS member in this analysis) on the calculated $\mathrm{PM}_{10}$ concentration can be analyzed a more complex way, when the effect of different parameters are taken into account simultaneously. This type of analysis is our next plan.

\section{Conclusion}

Results confirm that the chemical transport model is suitable for the detailed examination of the relationship between air pollutant concentrations and meteorological elements. Through model simulations, we demonstrated that a local accumulation of air pollutants significantly depends on the current meteorological conditions. A modification of the values of key meteorological variables that dominate in the dispersion processes - such as precipitation, wind speed, and planetary boundary layer height - brings about a consistent change in air concentrations.

The strengthening of wind speed causes the accumulated air pollutants to diffuse, thereby leading to an improvement in air quality and vice versa, decreasing wind speeds favor the accumulation of pollutants and induce a decline in air quality. Our studies showed that the differences in the concentration fields due to the modified meteorology are more pronounced in the case of lower wind speeds than they are in the case of higher wind speeds. Boundary layer characteristics play also a crucial role in the dilution of air pollutants near the surface. Increasing boundary layer height is coupled with the decrease of pollutant concentrations and, on the other hand, a decrease in the planetary boundary layer height leads to a definite increase in concentrations. Our studies showed that the differences in the concentration fields due to the modified meteorology are more pronounced in the case of higher boundary layer than they are in the case of lower boundary layer height.

Concerning the examined weather elements, the general conclusion can be deducted that they fundamentally influence the formation of air pollution and affect air concentrations significantly. The wind speed, being in connection with the intensity of mixing in the air and the height of the planetary boundary layer are both inversely proportional to the amount of pollutants in the air. Weather situations coupled with low wind speed, low boundary layer height, and without precipitation favor the accumulation of air pollutants the most. On the other hand, stronger winds and an increase in the boundary layer height cause concentrations to decrease. Based on the results, the role of local meteorology is therefore significant in the formation of air pollution. The more knowledge we have about the relationship between local weather and the evolving air concentrations, the more accurate assessments we are able to accomplish regarding both the current air quality and air quality forecasts. 
Therefore, a detailed exploration of these relations is of fundamental significance. Naturally, the geographical environment, that makes the individual local conditions diverse, is also an important factor in this issue. The Carpathian Basin is unique in this respect with strong characteristics as a basin, but within its boundaries very different local conditions may exist in connection with the diverse topography, that is necessary to be taken into account.

The investigation of similar cases is essential in order to explore weather situations in which we can only reservedly rely on the results of air quality models. Being aware of the limitations of our models and the situations in which their calculations might become imprecise, and knowing what to expect concerning the differences between the real situation and the model results - whether the model over- or underestimates the real concentrations - make it possible for us to assign an uncertainty to the results and also to make a more accurate assessment of the current situation by taking the expectable inaccuracies into account, based on which we can introduce more adequate measures.

Acknowledgements: This work was supported by the GINOP-2.3.2-15-2016-00055 project, financed by the Ministry of Finance. The authors are grateful to Réka Suga and Katalin Jávorné Radnóczi, who helped this research with producing of the AROME EPS data.

\section{References}

Apte, J.S., Messier, K.P., Gani, S., Brauer, M., Kirchstetter, T.W., Lunden, M.M., Marshall, J.D., Portier, C.J., Vermeulen, R.C.H., and Hamburg, S.P., 2017: High-resolution air pollution mapping with Google street view cars: exploiting big data. Environ. Sci. Technol. 51, 6999-7008. https://doi.org/10.1021/acs.est.7b00891

Angevine, W.M., Bioude, J., McKeen, S., and Holloway, J.S., 2014: Uncertainty in Lagrangian pollutant transport simulations due to meteorological uncertainty from a mesoscale WRF ensemble. Geosci. Model Develop. 7, 2817-2829. https://doi.org/10.5194/gmd-7-2817-2014

Baklanov, A., Schlünzen, K., Suppan, P., Baldasano, J., Brunner, D., Aksoyoglu, S., Carmichael, G., Douros, J., Flemming, J., Forkel, R., Galmarini, S., Gauss, M., Grell, G., Hirtl, M., Joffre, S., Jorba, O., Kaas, E., Kaasik, M., Kallos, G., Kong, X., Korsholm, U., Kurganskiy, A., Kushta, J., Lohmann, U., Mahura, A., Manders-Groot, A., Maurizi, A., Moussiopoulos, N., Rao, S.T., Savage, N., Seigneur, C., Sokhi, R.S., Solazzo, E., Solomos, S., Sørensen, B., Tsegas, G., Vignati, E., Vogel, $B$., and Zhang, Y., 2014: Online coupled regional meteorology chemistry models in Europe: current status and prospects. Atmos. Chemis. Phys. 14, 317-398.

https://doi.org/10.5194/acp-14-317-2014

Borrego, C., Monteiro, A., Ferreira, J., Miranda, A. I., Costa, A.M., Carvalho, A.C., and Lopes, M., 2008: Procedures for estimation of modelling uncertainty in air quality assessment. Environ. Int. 34, 613-620. https://doi.org/10.1016/j.envint.2007.12.005

De Marco, A., Proietti, C., Anav, A., Ciancarella, L., D'Elia, I., Fares, S., Fornasierb, M.F., Fusaroe, L., Manese, M.G.F., Marchettof, A., Mirceac, M., Paolettig, E., Piersantic, A., Rogoraf, M., Salvatid, L., Salvatorie, E., Screpantih, A., Vialettoc, G., Vitalee, M., and Leonardi, C., 2019: Impacts of air pollution on human and ecosystem health, and implications for the National Emission Ceilings Directive: Insights from Italy. Environ. Int. 125, 320-333. https://doi.org/10.1016/j.envint.2019.01.064

Du, C., Liu, S., Yu, X., Li, X., Chen, C., Peng, Y., Dong, Y., Dong, Z., and Wang, F., 2013: Urban Boundary Layer Height Characteristics and Relationship with Particulate Matter Mass Concentrations in Xi'an, Central China. Aerosol Air Qual. Res. 13, 1598-1607.

https://doi.org/10.4209/aaqr.2012.10.0274 
EEA (European Environment Agency), 2019: Air quality in Europe - 2019 report. EEA Report, No. 10/2019, ISSN 1977-8449, ISBN 978-92-9480-088-6, doi: 10.2800/822355

Ferenczi Z., Homolya E., and Bozó L., 2020: Detailed Assessment of a Smog Situation Detected in the Sajó Valley, Hungary. In (eds. Mensink C., Gong W., Hakami A.) Air Pollution Modeling and its Application XXVI. ITM 2018. Springer Proceedings in Complexity. Springer, Cham. https://doi.org/10.1007/978-3-030-22055-6_56

Guenther, A., Karl, T., Harley, P., Wiedinmyer, C., Palmer, P.I., and Geron, C., 2006: Estimates of global terrestrial isoprene emissions using MEGAN (Model of Emissions of Gases and Aerosols from Nature). Atmos. Chem. Phys. 6, 3181-3210. https://doi.org/10.5194/acp-6-3181-2006

Hauglustaine, D.A., Hourdin, F., Jourdain, L., Filiberti, M.-A., Walters, S., Lamarque, J.-F., and Holland, E.A., 2004: Interactive chemistry in the Laboratoire de Meteorologie Dynamique general circulation model: Description and background tropospheric chemistry evaluation. $J$. Geophys. Res. 109, D04314. https://doi.org/10.1029/2003JD003957

Holnicki, P. and Nahorski, Z., 2015: Emission data uncertainty in urban air quality modeling-case study. Environ. Model. Assess. 20, 583-597. https://doi.org/10.1007/s10666-015-9445-7

Homolya, E., 2021: A levegőminőség várható alakulásának vizsgálata újgenerációs diszperziós modellek alkalmazásával, PhD Thesis, Hungarian University of Agriculture and Life Sciences (In Hungarian)

Hourdin, F., Musat, I., Bony, S., Braconnot, P., Codron, F., Dufresne, J.L., Fairhead, L., Filiberti, M. A., Friedlingstein, P., Grandpeix, J.Y., Krinner, G., LeVan, P., Li, Z.X., and Lott, F., 2006: The LMDZ4 general circulation model: climate performance and sensitivity to parametrized physics with emphasis on tropical convection. Climate Dynam. 27, 787-813. https://doi.org/10.1007/s00382-006-0158-0

Kucera, V. and Fitz, S., 1995: Direct and indirect air pollution effects on materials including cultural monuments. Water, Air Soil Pollut 85, 153-165. https://doi.org/10.1007/BF00483697

Kukkonen, J., Pohjola, M., Sokhi, R. S., Luhana, L., Kitwiroon, N., Fragkou, L., Rantamäki, M., Berge, E., Ødegaard, V., Slørdal, L. H., Denby, B., and Finardi, S., 2005: Analysis and evaluation of selected local-scale PM10 air pollution episodes in four European cities: Helsinki, London, Milan and Oslo. Atmos. Environ. 39, 2759-2773. https://doi.org/10.1016/j.atmosenv.2004.09.090

Landrigan, P.J., 2017: Air pollution and health. Lancet Publ. Health 2, e4-e5. https://doi.org/10.1016/S2468-2667(16)30023-8

Lelieveld, J., 2017: Clean air in the Anthropocene. Faraday Discuss. 200, 693-703. https://doi.org/10.1039/C7FD90032E

Loveland, T.R., Reed, B.C., Brown, J.F., Ohlen, D.O., Zhu, Z., Yang, L.W.M.J., and Merchant, J.W., 2000: Development of a global land cover characteristics database and IGBP DISCover from 1 km AVHRR data. Int. J. Remote Sens. 21, 1303-1330. https://doi.org/10.1080/014311600210191

Mailler, S., Menut, L., Khvorostyanov, D., Valari, M., Couvidat, F., Siour, G., Turquety, S., Briant, R., Tuccella, P., Bessagnet, B., Colette, A., Létinois, L., Markakis, K., and Meleux, F., 2017: CHIMERE-2017: from urban to hemispheric chemistry-transport modeling. Geosci.Model Develop. 10, 2397-2423. https://doi.org/10.5194/gmd-10-2397-2017

Menut, L., Goussebaile, A., Bessagnet, B., Khvorostiyanov, D., and Ung, A., 2012: Impact of realistic hourly emissions profiles on air pollutants concentrations modelled with CHIMERE. Atmos. Environ. 49, 233-244. https://doi.org/10.1016/j.atmosenv.2011.11.057

Moiseenko, T.I., Dinu, M.I., Gashkina, N.A., Jones, V., Khoroshavin, V.Y., and Kremleva, T.A., 2018: Present status of water chemistry and acidification under nonpoint sources of pollution across European Russia and West Siberia. Environ. Res. Lett. 13, 105007.

https://doi.org/10.1088/1748-9326/aae268

Napelenok, S.L., Foley, K.M., Kang, D., Mathur, R., Pierce, T., and Rao, S.T., 2011: Dynamic evaluation of regional air quality model's response to emission reductions in the presence of uncertain emission inventories. Atmos. Environ. 45, 4091-4098. https://doi.org/10.1016/j.atmosenv.2011.03.030

Rybarczyk, Y. and Zalakeviciute, R., 2018: Machine learning approaches for outdoor air quality modelling: A systematic review. Appl. Sci. 8, 2570. https://doi.org/10.3390/app8122570

Szintai, B., Szücs, M., Randriamampianina, R., and Kullmann, L., 2015: Application of the AROME non-hydrostatic model at the Hungarian Meteorological Service: Physical parameterizations and ensemble forecasting. Idöjárás 119, 241-265. 